\title{
Small changes in bone structure of female $a 7$ nicotinic acetylcholine receptor knockout mice
}

\author{
Katrin S Lips ${ }^{1 *}$, Özcan Yanko ${ }^{1}$, Mathias Kneffel', Imke Panzer', Vivien Kauschke', Maria Madzharova ${ }^{1}$, Anja Henss², \\ Peter Schmitz ${ }^{2}$, Marcus Rohnke ${ }^{2}$, Tobias Bäuerle ${ }^{3}$, Yifei Liư ${ }^{4}$, Marian Kampschulte ${ }^{5}$, Alexander C Langheinrich ${ }^{6}$, \\ Lutz Dürselen ${ }^{7}$, Anita Ignatius ${ }^{7}$, Christian Heiss ${ }^{8}$, Reinhard Schnettler ${ }^{1,8}$ and Olaf Kilian ${ }^{1,9}$
}

\begin{abstract}
Background: Recently, analysis of bone from knockout mice identified muscarinic acetylcholine receptor subtype M3 (mAChR M3) and nicotinic acetylcholine receptor (nAChR) subunit a2 as positive regulator of bone mass accrual whereas of male mice deficient for a7-nAChR (a7KO) did not reveal impact in regulation of bone remodeling. Since female sex hormones are involved in fair coordination of osteoblast bone formation and osteoclast bone degradation we assigned the current study to analyze bone strength, composition and microarchitecture of female a7KO compared to their corresponding wild-type mice (a7WT).

Methods: Vertebrae and long bones of female 16-week-old a7KO $(n=10)$ and a7WT $(n=8)$ were extracted and analyzed by means of histological, radiological, biomechanical, cell- and molecular methods as well as time of flight secondary ion mass spectrometry (ToF-SIMS) and transmission electron microscopy (TEM).

Results: Bone of female a7KO revealed a significant increase in bending stiffness $(p<0.05)$ and cortical thickness $(p<0.05)$ compared to a7WT, whereas gene expression of osteoclast marker cathepsin $\mathrm{K}$ was declined. ToF-SIMS analysis detected a decrease in trabecular calcium content and an increase in $\mathrm{C}_{4} \mathrm{H}_{6} \mathrm{~N}^{+}(p<0.05)$ and $\mathrm{C}_{4} \mathrm{H}_{8} \mathrm{~N}^{+}(p<0.001)$ collagen fragments whereas a loss of osteoid was found by means of TEM.

Conclusions: Our results on female a7KO bone identified differences in bone strength and composition. In addition, we could demonstrate that a7-nAChRs are involved in regulation of bone remodelling. In contrast to mAChR M3 and nAChR subunit a2 the a7-nAChR favours reduction of bone strength thereby showing similar effects as a7ß2-nAChR in male mice. nAChR are able to form heteropentameric receptors containing $\alpha$ - and $\beta$-subunits as well as the subunits $a 7$ can be arranged as homopentameric cation channel. The different effects of homopentameric and heteropentameric a7-nAChR on bone need to be analysed in future studies as well as gender effects of cholinergic receptors on bone homeostasis.
\end{abstract}

Keywords: Nicotinic receptor, Bone strength, Bending stiffness, Cathepsin K, ToF-SIMS, Osteoid, Knockout mice, Micro-CT

\section{Background}

Acetylcholine acts as a neuronal as well as a non-neuronal signaling molecule through binding to nicotinic (nAChR) and muscarinic acetylcholine receptor (mAChR). nAChR are ligand gated cation channels build up by 5 subunits [1]. The composition of subunits in nAChRs determines ligand specificity, ligand affinity, cation permeability, and channel kinetics [2]. nAChR formed by $\alpha 1, \beta 1, \gamma, \delta$ and $\varepsilon$ subunits are called the muscle type of nAChR that is

\footnotetext{
*Correspondence: Katrin.S.Lips@chiru.med.uni-giessen.de

${ }^{1}$ Laboratory for Experimental Trauma Surgery, Justus-Liebig University

Giessen, Kerkraderstr. 9, 35394 Giessen, Germany

Full list of author information is available at the end of the article
}

particularly localized in the skeletal motor unit. The neuronal type of $n A C h R$ is present in the central nervous system and non-neuronal cells. nAChR are built up as heteropentamers by $\alpha$ - and $\beta$-subunits ( $\alpha 2-7, \beta 2-4)$, as homopentamers by $\alpha$-subunits $(\alpha 7, \alpha 9)$ and as $\alpha$-heteropentamers by different $\alpha$-subunits $(\alpha 9 \alpha 10, \alpha 7 \alpha 10)$ [3,4]. Bajayo et al. reported that mice deficient of the $\mathrm{nAChR}$ subunit $\alpha 2$ have increased bone resorption and low bone mass [5]. Several nAChR subunits and $\mathrm{mAChR}$ occur in bone tissue [6-8]. Besides nAChR subunit $\alpha 2 \mathrm{mAChR}$ are also involved in bone mass regulation. Activation of mAChR subtype M3 (M3R) leads to an increase in bone biomechanics, collagen synthesis, formation of trabeculae $[9,10]$ as well as a decrease in bone 
resorption [9]. Thus, the mAChR M3 as well as the nAChR subunit $\alpha 2$ has been identified as positive regulator of bone mass accrual. In our previous study we compared the bone of male mice deficient for $\alpha 7-\mathrm{nAChR}(\alpha 7 \mathrm{KO})$ compared to their corresponding wild-type mice $(\alpha 7 \mathrm{WT})$ where we did not find significant differences [10]. Since alterations in the collagen expression in the skin of $\alpha 7 \mathrm{KO}$ [11] were demonstrated and regulations of bone mass is most prominent in females (e.g. osteoporosis) [12] we decided to conduct a study where the bone of female $\alpha 7 \mathrm{KO}$ is analyzed. In addition to the gender change we also included some complementary methods. One of them was "time of flight secondary ion mass spectrometry" (ToF-SIMS) for quantification of bone calcium ion $\left(\mathrm{Ca}^{2+}\right)$ content and proline fragments that is one of the main amino acids of collagen [13-16]. The principle of ToF-SIMS is that primary ions hit the sample surface, releasing secondary ions from the surface, that were collected by an analyzer for producing single mass spectra and mass images of the sample surface [14]. Besides ToF-SIMS, several cell and molecular biological methods were used to analyze the bone microstructure and strength for which we could determine an increase in bone mass in female $\alpha 7 \mathrm{KO}$.

\section{Methods}

\section{Animals}

Female Chrna7 knockout mice (originally described by Orr-Urtreger et al. [17] on a C57BL/6 J background were derived from heterozygous breeding of animals obtained from Jacksons Laboratories (Bar Habor, ME, USA). Female 16 weeks old non-transgenic $(\alpha 7 \mathrm{WT}, \mathrm{n}=8)$ and homozygous null mice $(\alpha 7 \mathrm{KO}, \mathrm{n}=10)$ from this cross were used in this study. Animal care and experimental procedures were performed in accordance to the Directive 2010/63/EU and approved by the local animal care committee (Regierungspräsidium Gießen V 54-19 c 20-15 (1) GI 20/28 Nr. 88/2009). The animals were kept under specified pathogen-free conditions in the local animal breeding facility under a 12 hour (h) light-dark cycle with free access to water and chow.

Mice were genotyped by PCR described earlier [18]. In brief DNA was extracted from tail snips using the DNeasy Kit (Qiagen, Hilden, Germany). PCR was performed using gene-specific primer pairs $(\alpha 7 \mathrm{WT}$ - and $\alpha 7 \mathrm{KO}$-forward primer: 5'-CCTGGTCCTGCTGTGTTAAACTGCTTC$3^{\prime}, \alpha 7$ WT reverse primer: $5^{\prime}$-CTGCTGGGAAATCCTAG GCACACTTGAG-3', $\alpha 7 \mathrm{KO}$ reverse primer: $5^{\prime}$-GACAA GACCGGCTTCCATCC-3') and the AmpliTaq Gold polymerase (Applied Biosystems, Branchburg, NJ, USA).

\section{Dual-energy X-ray absorptiometry (DXA)}

Bone mineral density (BMD; $\mathrm{g} / \mathrm{cm}^{2}$ ) of left femur, spinal column, and the whole skeleton were measured directly after euthanasia of the animals by DXA scan (lunar prodigy, GE Healthcare, Germany). Analysis was performed using the small-animal mode of the encore software (GE Healthcare, version 13.40) and was calibrated at each start of the experiment.

\section{D Micro-CT}

The right femora, vertebrae Th13 and L1 were scanned with a high-resolution microtomographic system (MicroCT 1072, SkyScan, Kontich, Belgium) at $16 \mu \mathrm{m}$ voxel size at 8 bit gray scale range as described earlier [10]. The three-dimensional microstructural properties of the trabecular bone region of interest in the metaphysis and the vertebral body were assessed by using the SkyScan-CTanalyser software (SkyScan). The following parameters were calculated: bone volume fraction (BV/TV), trabecular thickness (Tb.Th), trabecular separation (Tb.Sp), trabecular number (Tb.N), structure model index (SMI), and bone surface density (BS/TV). In addition, the average cortical thickness was calculated. Mid-diaphyseal cortical area (Ct.Ar), relative cortical bone area to tissue area (CT. Ar./Tt.Ar), and average cortical thickness (Ct.Th) were obtained from a stack of 200 axial slices of the right femur.

\section{Biomechanical analysis of femoral bones}

The mechanical properties of the diaphysis of femoral bones were evaluated by three-point bending test as described earlier $[10,19]$. In brief, the proximal femur was secured in a hinge joint after potting in dental cement. The distal end was positioned with the femoral condyles on a cylindrical support. Subsequently the bending load was introduced midway between both femoral ends until failure occurred. Bending stiffness $\left(\mathrm{S}\right.$ in $\mathrm{Nmm}^{2}$ ), maximal strain $\left(\sigma_{u}\right.$ in $\left.\mathrm{MPa}\right)$ and elasticity modulus ( $E$ in $\mathrm{GPa}$ ) were calculated using the linear slope of the loaddeformation curve.

\section{Dynamic contrast-enhanced magnetic resonance imaging (DCE-MRI)}

MRI was performed on a $1.5 \mathrm{~T}$ MR-scanner (Symphony, Siemens, Germany) using an appropriate home-built coil for radiofrequency excitation and detection. The animals were imaged using a saturation recovery turbo flash sequence for dynamic contrast-enhanced imaging (orientation axial, TR $13 \mathrm{~ms}$, TE $5.3 \mathrm{~ms}$, Ti $300 \mathrm{~ms}$, slice thickness $2 \mathrm{~mm}$, TOV $60 \times 60 \mathrm{~mm}^{2}$, matrix 128 , measuring time 14:55 min) while infusing $0.1 \mathrm{mmol} / \mathrm{kg} \mathrm{Gd}$-DTPA (Magnevist, Schering) i.v. over a time period of 10 seconds. The vascular parameters amplitude A [arbitrary units], associated with relative blood volume) and exchange rate constant Kep ([1/min], reflecting vessel permeability) were calculated from DCE-MRI data according to the pharmacokinetic two-compartment model of Brix et al. [20]. Analysis was done using Dynalab workstation (Mevis Research, 
Table 1 Primer pairs used for real-time RT-PCR

\begin{tabular}{|c|c|c|c|c|}
\hline Primer & Sequence & Length $[b p]$ & Annealing temp. $\left[{ }^{\circ} \mathrm{C}\right]$ & GenBank ID (accession) \\
\hline Col1a1 ${ }^{a}$ for & TGCCTGGCGGACTTCCTGGT & 144 & 62 & NM_007742.3 \\
\hline rev & CCGGCACCTGGCTTAGGTGG & & & \\
\hline Colla $2^{b}$ for & ATGCCGGTCGACCTGGGGAA & 144 & 60 & NM_007743.2 \\
\hline rev & GTCCAGCTGGGCCGATTGGG & & & \\
\hline Ctsk for & GAGGCGGCTATATGACCACT & 119 & 58 & NM_007802.3 \\
\hline rev & CTITGCCGTGGCGTTATACA & & & \\
\hline Bglap $^{d}$ for & TTCTGCTCACTCTGCTGACC & 111 & 58 & NM_007541.2 \\
\hline rev & TATTGCCCTCCTGCTTGGAC & & & \\
\hline ALP for & TTAAGGGCCAGCTACACCAC & 150 & 58 & NM_007431.2 \\
\hline rev & CCTTCACGCCACACAAGTAG & & & \\
\hline BActin for & TGTTACCAACTGGGACGACA & 165 & 58 & NM_007393.3 \\
\hline rev & GGGGTGTTGAAGGTCTCAAA & & & \\
\hline
\end{tabular}

${ }^{\mathrm{a} C o l 1 a 1:}$ Collagen 1a1, ${ }^{\mathrm{b}} \mathrm{Col1a2:}$ Collagen 1a2, ${ }^{\mathrm{C}} \mathrm{CtsK}$ : Cathepsin $\mathrm{K},{ }^{\mathrm{d}} \mathrm{Bg}$ lap: Osteocalcin, ${ }^{\mathrm{e}} \mathrm{ALP}$ : alkaline phosphatase.

Bremen, Germany) drawing regions of interest (ROIs) manually in the lumbar L5 vertebrae, pelvis and femur.

\section{Histology, transmission electron microscopy (TEM)}

Right tibia and vertebrae L3 were fixed in 4\% phosphatebuffered paraformaldehyde (PFA, Merck, Darmstadt, Germany), decalcified with 10\% EDTA, dehydrated in an increasing series of ethanol, embedded in paraffin and cut with a rotations microtome (Leica RM2155, Wetzlar, Germany) in 3-5 $\mu \mathrm{m}$ thick sections. Sections were processed for standard hematoxylin-eosin staining, enzymeand immunohistochemistry.

Sections of vertebrae L4 were used for histology and transmission electron microscopy (TEM). Samples were fixed in yellow fix ( $2 \%$ paraformaldehyde, $2 \%$ glutaraldehyde, $0.02 \%$ picric acid) for 6 hours (h), washed several times with $0.1 \mathrm{M}$ cacodylate buffer ( $\mathrm{pH} 7.2$ ), incubated in $1 \%$ osmium tetroxide $\left(\mathrm{OsO}_{4}\right.$, Fluka, Buchs, Switzerland) and dehydrated in a series of graded ethanol. Subsequently, the samples were embedded in Epon (Serva, Heidelberg, Germany) and cut with an ultracut (ReichertJung, Germany). Semithin sections with a thickness of $0.5-1 \mu \mathrm{m}$ were used for histology and ToF-SIMS analysis. For ultrastructural evaluations sections were cut at a thickness of 70-80 nm, counterstained with uranyl acetate and lead citrate (Reichert Ultrastainer, Leica, Germany), and examined in a Zeiss EM 109 transmission electron microscope and a digital camera (2 K, Zeiss, Oberkochen, Germany).

\section{Enzyme- and immunohistochemistry}

Deparaffinized sections of L3 were used for enzyme histochemical staining of tartrate-resistant acidic phosphatase (TRAP) to identify osteoclasts and macrophages. In brief, sections were preincubated in sodium acetate buffer $(\mathrm{pH} 5.2)$ for $10 \mathrm{~min}$ and then incubated for $30 \mathrm{~min}$ at $37^{\circ} \mathrm{C}$ in a solution of Naphtol AS-TR phosphate (SigmaAldrich, Taufkirchen, Germany), NN-Dimethylformamid (Sigma-Aldrich), and sodium tartrat (Merck, Darmstadt, Germany) with fast red TR-salt (Sigma-Aldrich). Sections not used for histomorphometrical analysis were counterstained with hematoxylin (Shandon Scientific Ltd, Cheshire, UK) and coverslipped with Kaisers Glyceringelatine (Merck).

For immunohistochemistry deparaffinized sections were preincubated for 5 min in $3 \% \mathrm{H}_{2} \mathrm{O}_{2}$ in Tris- $\mathrm{HCl}$ buffer (pH 7.4) with 5\% Triton-X-100 (TBS) to block the endogenous peroxidase. After carefully washing the following primary antibodies were processed overnight in dilution buffer (Dako, Glostrup, Denmark) at $4^{\circ} \mathrm{C}$ : a) collagen type 1

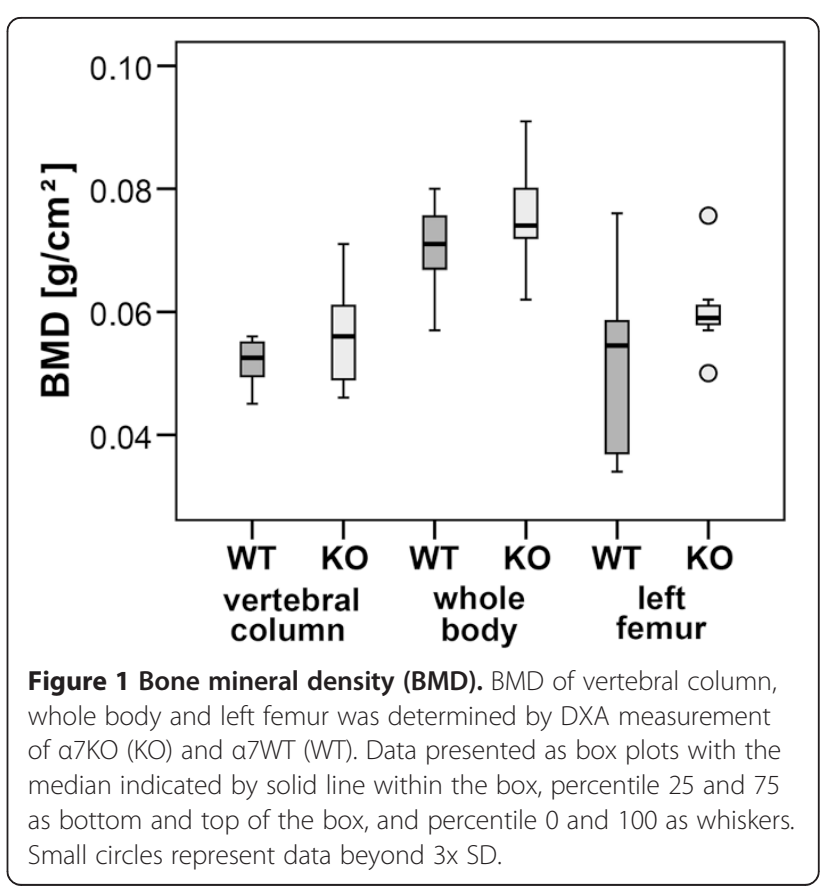


(1:500 diluted, Biomex, Mannheim, Germany), b) PECAM1 (CD31, 1:100 diluted, Acris, Herford, Germany), and c) smooth muscle actin (SMA, 1:100 diluted; Acris). After rinsing sections were incubated with goat anti-rabbit secondary antibody (1:500; Vector, Burlingame, California, USA) for $30 \mathrm{~min}$ and afterwards with the ABC complex/ horseradish peroxidase labeled avidin (Dako) also for $30 \mathrm{~min}$. Peroxdiase activity was visualized with Nova Red (Vector). Counterstaining of nuclei was performed with hematoxylin.

\section{Histomorphometric analysis}

TRAP stained sections of vertebrae L3 were digitalized with an Axioplan-2 Microscope (Zeiss, Jena, Germany) equipped with a DC500 camera (Leica, Wetzlar, Germany) and analyzed with the open-source software TRAP Histo [21]. According to [22] the relative osteoclast parameter a) osteoclast surface/bone surface (Oc.S/BS), b) osteoclast number/bone surface (N.Oc/BS), c) osteoclast number/ bone volume (N.Oc/BV), and d) osteoclast number/tissue volume (N.Oc/TV) were calculated.

Real-time reverse transcriptase polymerase chain reaction (real-time RT-PCR)

Vertebrae L3 were transferred into RNAlater ${ }^{\circ}$ (Applied Biosystems/Ambion, Austin, USA) directly after euthanasia. RNA isolation, removal of genomic DNA contaminations, cDNA synthesis as well as real-time RT-PCR with gene specific primers (Table 1, MWG, Ebersberg, Germany) were performed as described earlier [10].

\section{ToF-SIMS}

The ToF-SIMS measurements were done with a TOF. SIMS 5-100 (IONTOF GmbH, Münster, Germany). The machine was equipped with a $25 \mathrm{keV}$ Bismuth cluster primary ion gun. Data evaluation is done with the software Surface Lab 6.2. For the measurement of qualitative mass images $\mathrm{Bi}^{+}$is used as primary ion species. The primary ion gun worked in the burst alignment (bi-ba-i)
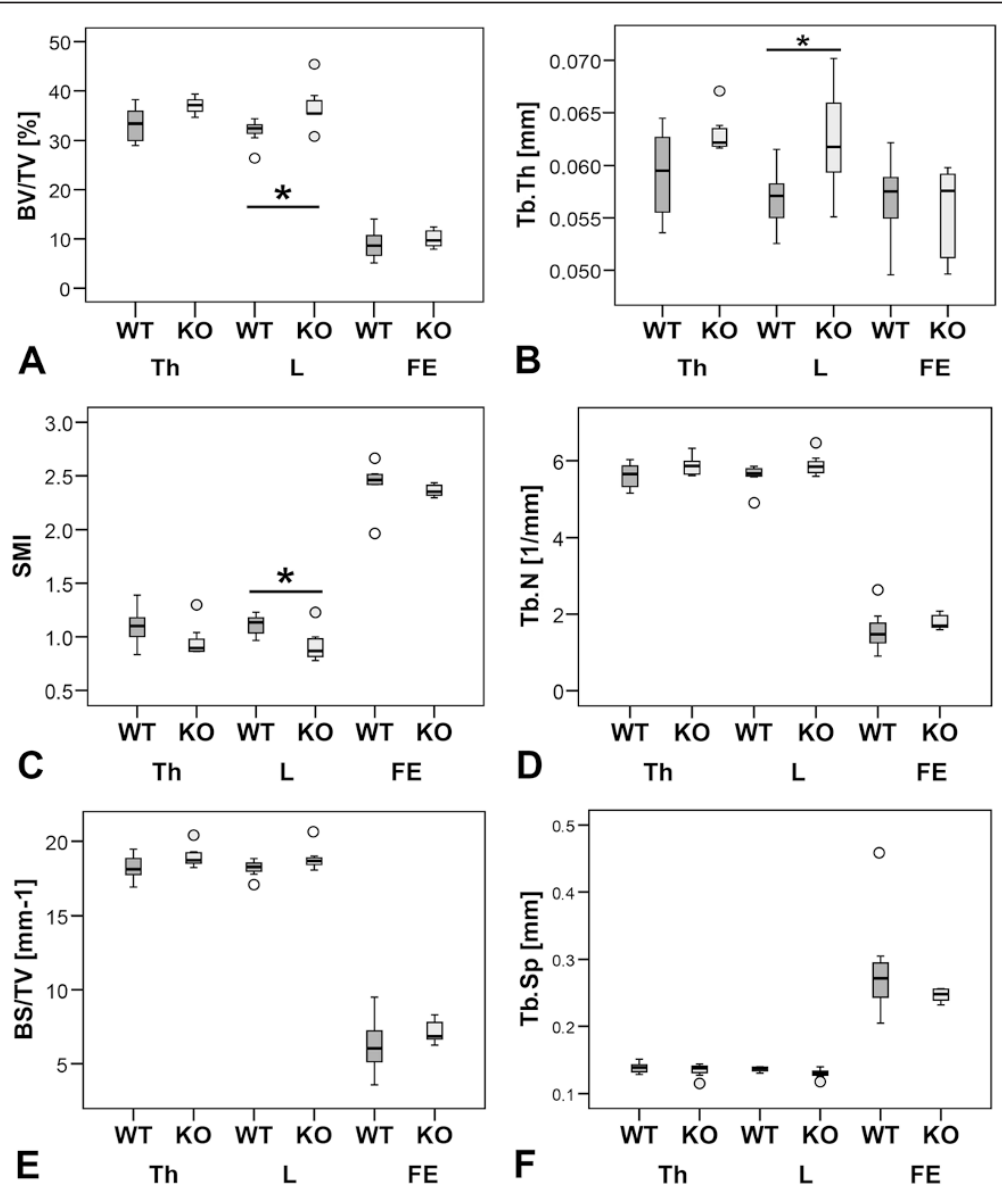

Figure 2 Bone microarchitecture. Bone volume fraction (BV/TV, A), trabecular thickness (Tb.Th,), structure model index (SMI, C), trabecular number (Tb.N, D), bone surface density (BS/TV, E), and trabecular separation (Tb.Sp, F) were measured for vertebrae Th13 (Th), L1 (L), and the right femora (FE) by means of micro-CT. ${ }^{*} p \leq 0.05$. Data presented as box plots with the median indicated by solid line within the box, percentile 25 and 75 as bottom and top of the box, and percentile 0 and 100 as whiskers. Small circles represent data beyond 3x SD. 
mode to obtain a lateral resolution of up to $300 \mathrm{~nm}$. The measured area covered $250 \times 250 \mu \mathrm{m}^{2}$ with a pixel number of $512 \times 512$ pixel. For each mass image 150 scans were added.

For the comparison of the trabecular composition $\mathrm{Bi}_{3}{ }^{+}$ was used as primary ion species. The gun worked in the high current bunched (bi-hc-bu) mode. Due to the comparably high sample charging always an area of $500 \times$ $500 \mu \mathrm{m}^{2}$ with $128 \times 128$ pixel was measured. In each case 100 scans were added to obtain a better contrast. From each sample we took mass images from three different areas. For getting a good statistic we defined on each mass image three so called regions of interest (ROI) of the size $20 \times 20 \mu^{2}$ on the trabecular network. Only the mass spectra from these areas were summed up and evaluated. By this method we got 9 data evaluation areas per sample. In total we investigated 6 samples of wild type mice and 6 samples of knockout mice.

For the detailed measurement of the trabecular network a higher magnification is necessary. Therefore we operated the primary ion gun in the burst alignment mode and used $\mathrm{Bi}^{+}$primary ions for getting higher primary ion currents. For the comparison of the composition of the trabecular edge with the center we measured areas of $31.3 \times 31.3 \mu \mathrm{m}$ with a pixel number of $128 \times 128$ pixel 50 times and defined again ROIs, which are located at the edge and in center of the trabeculae. Again the mass spectra of these ROIs were added and evaluated. From each sample we took two mass images and defined in each mass image two ROIs at the edge and two ROIs in the center of the trabeculae.

These semi-quantitative evaluations are based on the fact that the count rates of mass signals are proportional to the real concentrations of the respective species.

\section{Statistical analysis}

The SPSS software (version 18.0; SPSS Institute Inc, Cicago, USA) was used for statistical analysis of realtime RT-PCR, histomorphometry, Micro-CT, DXA, and ToF-SIMS. Comparisons were performed by KruskalWallis non-paramteric analysis of variance followed by the Mann-Whitney test. For statistical analyses of DCEMRI, means and medians of parameters A and Kep were calculated for each region per group (threshold was set to be 1.5 [arbitrary units] for parameter $A$ and $100[1 / \mathrm{min}$ ] for parameter Kep). Statistical comparison between the groups was performed for all ROIs using the $t$ test (SigmaStat 3.5, Systat SigmaPlot v11.1, Systat Software Inc.). A p value of less than 0.05 was taken as a significant difference.

\section{Results}

\section{Bone strength}

DXA scans did not show any significant differences in BMD (Figure 1). 3D Micro-CT analyses of the trabecular region of Th13, L1 and femur did not determine a clear result. No differences were measured for Th13
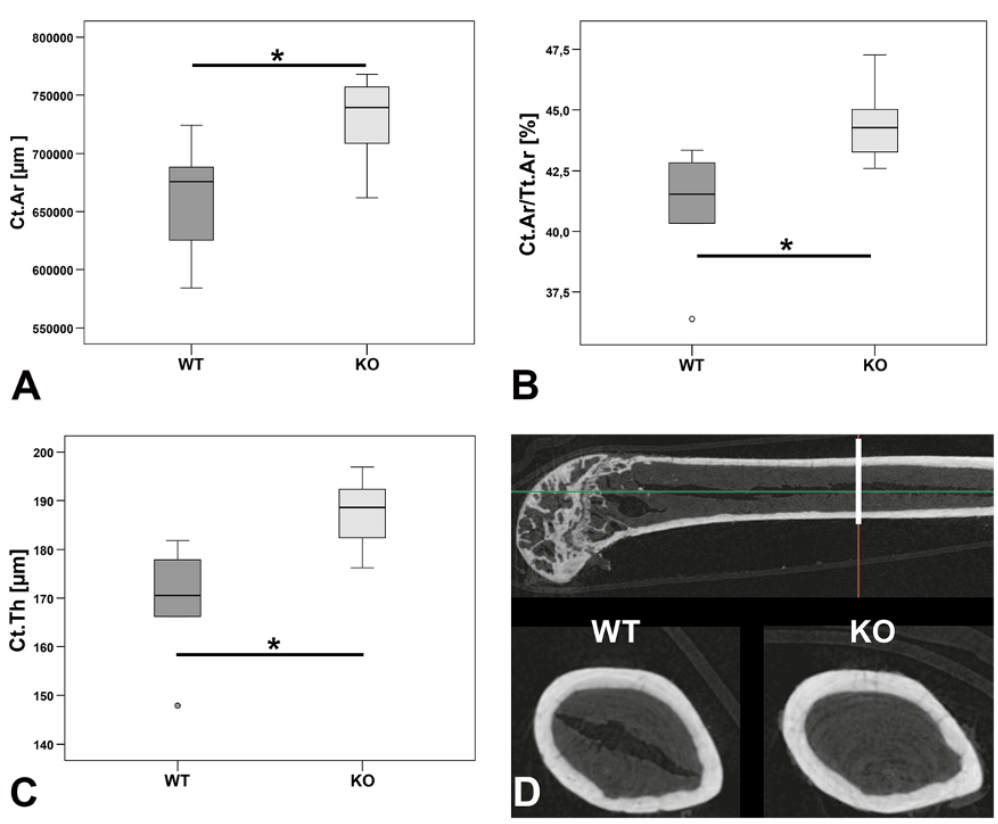

Figure 3 Cortical bone parameters. Cortical area (Ct.Ar, A), relative cortical bone area to tissue area (Ct.Ar/Tt.Ar, B), and average cortical thickness (Ct.Th, C) were obtained from 200 axial slices of the mid-diaphyseal area of right femora (D). Data presented as box plots with the median indicated by solid line within the box, percentile 25 and 75 as bottom and top of the box, and percentile 0 and 100 as whiskers. ${ }^{*} p \leq 0.05$. Small circles represent data beyond 3x SD. 
and femur whereas L1 showed an increase in BV/TV $(\mathrm{p}<0.05$, Figure $2 \mathrm{~A})$ and Tb.Th $(\mathrm{p}<0.05$, Figure $2 \mathrm{~B})$ and a reduction in SMI $(p=0.056$, Figure $2 \mathrm{C})$ of $\alpha 7 \mathrm{KO}$. No differences were detected for Tb.N ( $>0.05$, Figure $2 \mathrm{D})$, BS/TV ( $>0.05$, Figure 2E), and Tb.Sp ( $p>0.05$, Figure 2F). The SMI of $\alpha 7 \mathrm{KO}$ reflected "plate-like" structures (SMI closer to 0 whereas $\alpha 7 \mathrm{WT}$ indicated "rod-like" structures, SMI closer to 3). 3D-Micro-CT analysis of the diaphysis resulted in a significant increase in cortical area (Ct.Ar, $\mathrm{p}<0.05$, Figure $3 \mathrm{~A}$ ), relative cortical bone area to tissue area (Ct.Ar/Tt.Ar, $\mathrm{p}<0.05$, Figure $3 \mathrm{~B}$ ), and average cortical thickness (Ct.Th, $\mathrm{p}<0.05$, Figure $3 \mathrm{C}$ ). In accordance with the increase in cortical bone parameters biomechanical testing with the three-point bending test revealed a significant increase in bending stiffness $(S, p<0.05)$, maximal strain $\left(\sigma_{U}, \mathrm{p}<0.05\right)$, and elasticity modulus $(E$, $\mathrm{p}<0.05$ ) of female $\alpha 7 \mathrm{KO}$ compared to $\alpha 7 \mathrm{WT}$ (Figure 4).

\section{Bone marrow microvascularization}

Functional parameters amplitude A and exchange rate constant Kep were analyzed in the bone marrow of lumbar vertebra L5, pelvis and femur, respectively using DCE-MRI and verified with immunohistochemistry of demineralized immunolabeled sections. None of the statistical comparison performed at any anatomical site (vertebra, pelvis, femur) with DCE-MRI measurements showed significant differences between the two groups (Figure 5, Table 2). Immunolabeling were performed with antibodies detecting smooth muscle actin (SMA) and the platelet endothelial cell adhesion molecule (PECAM-1, CD31) to mark blood vessels (Figure 5D-E). Only few vessels were observed in the cortical as well as in the cancellous bone.

\section{Resorption capacity}

Bone resorption was evaluated by real-time RT-PCR analysis using primers for the osteoclast marker cathepsin $\mathrm{K}$ that showed a significant decrease in $\alpha 7 \mathrm{KO}(59 \%, \mathrm{p}<0.05$, Figure 6). TRAP enzyme histochemistry was used for labeling of osteoclasts, mono- and multinucleated macrophages. Histomorphometric osteoclast parameters were determined according to $[21,22]$. No significant differences were measured for Oc.S/BS (p > 0.05), N.Oc/BS ( $>>0.05)$, N.Oc/BV $(\mathrm{p}>0.05) ; \mathrm{N} . \mathrm{Oc} / \mathrm{TV}(\mathrm{p}>0.05)$ (Figure 7$)$.

\section{Analysis of bone formation}

On the molecular level no significant differences in bone formation were determined. Real-time RT-PCR revealed no regulation of mRNA expression for the osteoblast markers alkaline phosphatase (ALP), osteocalcin (OC), Collagen $1 \alpha 1$ (Col1 $\alpha 1$ ), and Collagen $1 \alpha 2$ (Col1 $\alpha 2)$ (Figure 6). ToF-SIMS analysis revealed a significant decrease in calcium ion content of trabecular center $(\mathrm{p}<0.05)$ and trabecular edge $(\mathrm{p}<0.001)$ in $\alpha 7 \mathrm{KO}$ compared to $\alpha 7 \mathrm{WT}$ (Figure 8). Combining edge and center of
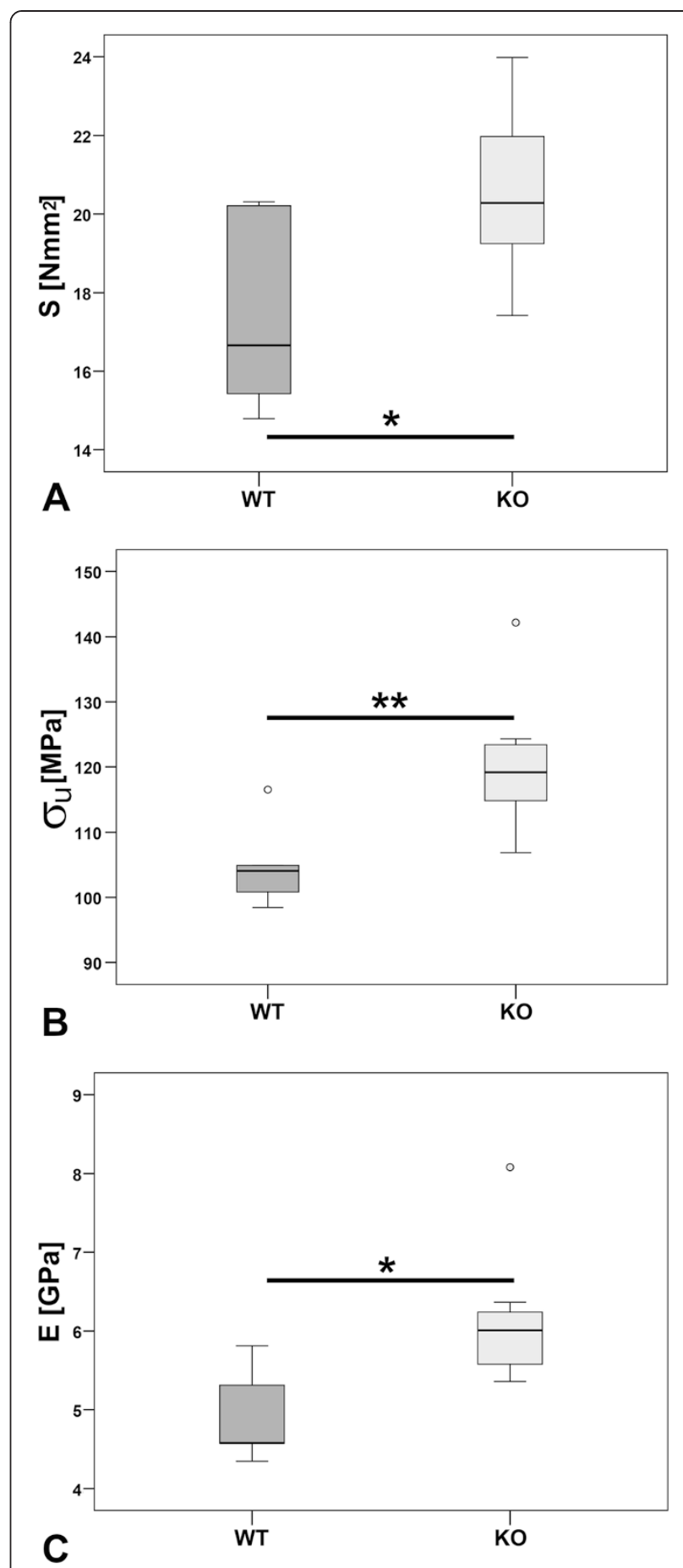

Figure 4 Biomechanical bone strength. Bending stiffness $\mathrm{S}$ in $\left(\mathrm{Nmm}^{2}, \mathbf{A}\right)$, maximal strain ( $\sigma_{\cup}$ in $\left.\mathrm{MPa}, \mathbf{B}\right)$, and elasticity modulus ( $\mathrm{E}$ in $\mathrm{GPa}, \mathbf{C}$ ) were calculated for femora of a7KO and a7WT by threepoint bending test. Data presented as box plots with the median indicated by solid line within the box, percentile 25 and 75 as bottom and top of the box, and percentile 0 and 100 as whiskers. ${ }^{*} p \leq 0.05$, ${ }^{* *} p \leq 0.01$. Small circles represent data beyond 3x SD. 


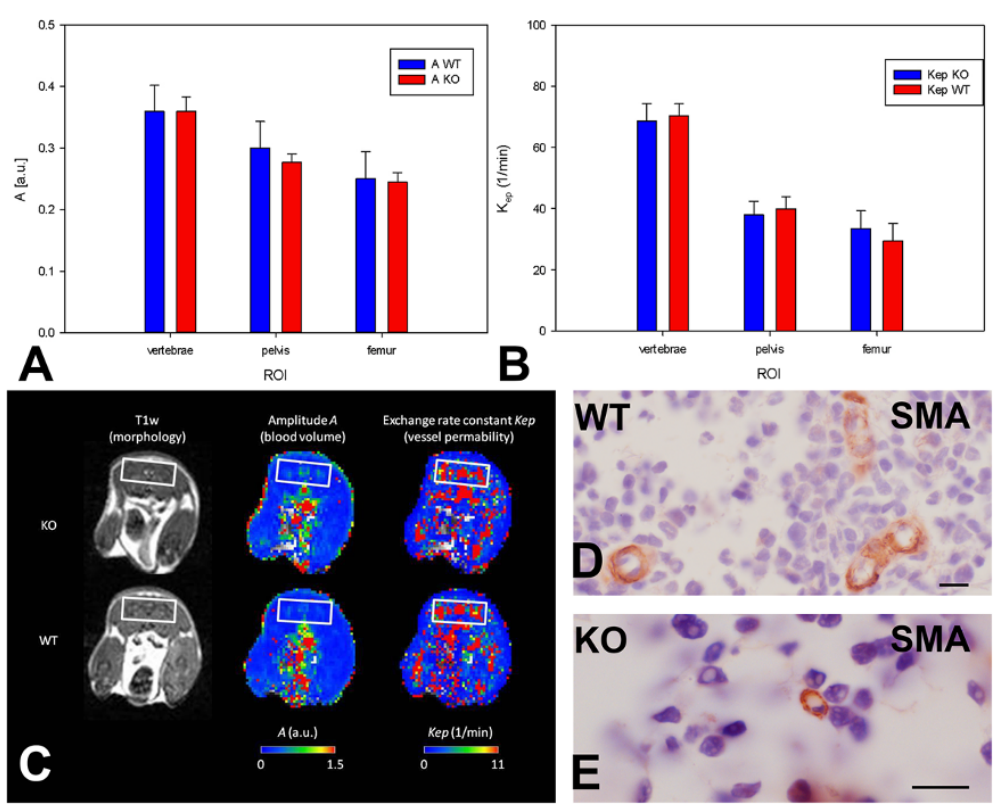

Figure 5 Bone marrow vascularization. Amplitude A (A) and exchange rate constant Kep (B) was acquired by dynamic contrast-enhanced magnetic resonance imaging (DCE-MRI; error bars: standard error) for a7KO (KO) and a7WT (WT). (C) Morphological images and color maps of parameters A and Kep acquired with T1 weighted morphological MRI and DCE-MRI from a7KO (upper row) and a7WT (lower row). All sections are shown in transversal orientation and contain the information of vascularization from the pelvis (white squares) as an example. The parameters are color-coded ranging from red (high values) to blue (low values). Immunohistochemical staining using a primary antibody against smooth muscle actin (SMA, red color) identified bone marrow vessels in a7WT (D) and a7KO (E) vertebrae L3. Bone marrow cells were counterstained with hematoxylin (purple). Bar: $10 \mu \mathrm{m}$.

trabeculae a significant increase of amnio acid proline fragments in $\alpha 7 \mathrm{KO}\left(\mathrm{C}_{4} \mathrm{H}_{6} \mathrm{~N}^{+} \mathrm{p}<0.05\right.$ and $\mathrm{C}_{4} \mathrm{H}_{8} \mathrm{~N}^{+} \mathrm{p}<$ 0.001) was measured (Figure 8). Using ultra-structural analysis by means of TEM no properly formed osteoid was found in $\alpha 7 \mathrm{KO}$ (Figure 9).

\section{Discussion}

In the current study we investigated bone strength, microarchitecture and composition of 16-week-old female $\alpha 7 \mathrm{KO}$ compared to corresponding wild-type mice. We demonstrated increased biomechanical strength (e.g. bending stiffness), alterations regarding some Micro-CT parameters of vertebrae L1, up-regulation of cortical parameters (e.g. cortical thickness) by means of Micro$\mathrm{CT}$, reduced mRNA expression of the osteoclast enzyme cathepsin $\mathrm{K}$, decreased trabecular calcium ion content and increased amounts of collagen fragments by means of ToF-SIMS, and no osteoid by means of TEM. Recently we investigated bones of male $\alpha 7 \mathrm{KO}$ mice compared to $\alpha 7 \mathrm{WT}$ by means of Micro-CT, biomechanical three-point bending test, and real-time RT-PCR [10]. Investigations of male bone did not result in significant differences between $\alpha 7 \mathrm{KO}$ and $\alpha 7 \mathrm{WT}$ [10]. Changes in bone mass were reported for gene deficient mice of mAChR M3 $[9,10]$,

Table 2 Quantitative DCE-MRI parameters

\begin{tabular}{|c|c|c|c|c|c|c|c|}
\hline \multirow[t]{2}{*}{ Group } & & \multicolumn{3}{|l|}{$A$ [a.u.] } & \multicolumn{3}{|c|}{ Kep $[1 / \mathrm{min}]$} \\
\hline & & Vertebra & Pelvis & Femur & Vertebra & Pelvis & Femur \\
\hline \multirow[t]{4}{*}{$\mathrm{KO}(\mathrm{n}=10)$} & Mean & 0.3599 & 0.2768 & 0.2446 & 70.3906 & 39.9560 & 29.4042 \\
\hline & Median & 0.3437 & 0.2904 & 0.2579 & 70.7894 & 39.2174 & 24.9314 \\
\hline & Std.dev & 0.0699 & 0.0407 & 0.0491 & 11.6716 & 12.3151 & 18.0503 \\
\hline & Std.err & 0.0233 & 0.0136 & 0.0155 & 3.8905 & 3.8944 & 5.7080 \\
\hline \multirow[t]{4}{*}{ WT $(n=8)$} & Mean & 0.3603 & 0.3002 & 0.2507 & 68.6066 & 37.9580 & 33.4469 \\
\hline & Median & 0.3291 & 0.2690 & 0.1958 & 68.7567 & 39.7596 & 31.3584 \\
\hline & Std.dev & 0.1013 & 0.1223 & 0.1244 & 13.9386 & 12.3716 & 16.3246 \\
\hline & Std.err & 0.0413 & 0.0433 & 0.0440 & 5.6904 & 4.3740 & 5.7716 \\
\hline
\end{tabular}

KO: mice with gene deficient of a7-nAChR, WT: corresponding wild-type mice. 


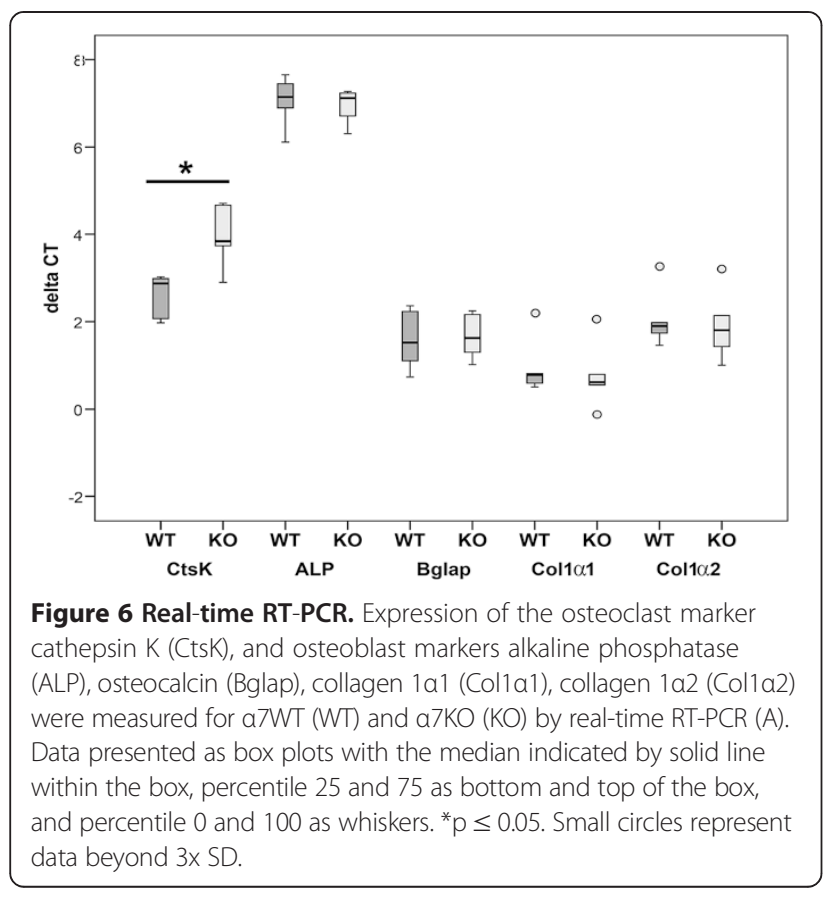

nAChR subunit $\alpha 2$ [5], and male $\alpha 7 \beta 2-n A C h R(\alpha 7 \beta 2 \mathrm{KO})$ [23]. Thus, it is supposed that AChRs are involved in bone mass regulation. Bone loss is often originated by an imbalance in bone remodelling where osteoclast bone degradation is excessive for osteoblast bone formation leading to bone disorders e.g. osteoporosis [12]. Since the strongest risk factor for postmenopausal osteoporosis is estrogen deficiency [12] we asked whether female 16-week-old $\alpha 7 \mathrm{KO}$ hold alterations of bone characteristics. Our current results on female bone of $\alpha 7 \mathrm{KO}$ did not demonstrate any sign of osteoporotic bone loss. On the contrary biomechanical three-point-bending test resulted in an up-regulation in bending stiffness of $\alpha 7 \mathrm{KO}$ compared to $\alpha 7 \mathrm{WT}$. In line with these results we measured an increased mid-shaft cortical thickness of the female $\alpha 7 \mathrm{KO}$ compared to $\alpha 7 \mathrm{WT}$ by means of Micro-CT. Male $\alpha 7 \mathrm{KO}$ did not reveal significant differences in biomechanical bone strength [10] whereas cortical thickness was not determined in our previous study. Thus, the current study showed indeed difference in bone strength of female $\alpha 7 \mathrm{KO}$ compared to $\alpha 7 \mathrm{WT}$ whereas male $\alpha \mathrm{KO}$ did not reveal alterations.

Measurement of biomechanical parameters is less common in clinical osteoporosis diagnosis whereas determination of BMD by means of DXA scan is most frequent. A decrease in BMD standard deviation of more than 2.5 below the adult mean value is taken as sign for osteoporosis [12]. Rodents with experimental bone loss provoked by e.g. ovariectomy showed a decline in BMD [24]. Regarding female $\alpha 7 \mathrm{KO}$ we could not determine an alteration in BMD. DXA scans for male $\alpha 7 \mathrm{KO}$ were not performed in our previous study [10]. In male 6-monthold $\alpha 7 \beta 2 \mathrm{KO}$ a significant increase of BMD was measured compared to wild-type mice [23]. Additionally, $\alpha 7 \beta 2 \mathrm{KO}$ presented an increased lean body mass, decreased size of adipocytes and glycemia whereas body weight, insulin secretion and sensitivity remained unaltered [23]. The metabolic effects could be originated by hyperactivity as described for central $\beta 2-n A C h R$ depletion $[23,25]$. Future analysis of $\alpha 7 \beta 2 \mathrm{KO}$ bone microarchitecture and composition will facilitate new insights in the role of $\mathrm{nAChR}$ in bone.

Application of nicotine that is an exogenous agonist of nAChR induced osteoblast cell proliferation $[6,26]$, increased gene expression of OC, Col1 11 and ALP in a human osteosarcoma cell line [26] whereas the expression of ALP in a murine osteoblast cell line was reduced [6]. We presently report that gene expression of osteoblast markers were not changed in female $\alpha 7 \mathrm{KO}$ compared to $\alpha 7 \mathrm{WT}$. This is in accordance with results of our previous study on male $\alpha 7 \mathrm{KO}$ where we also did not measure changes in Col1 $\alpha 1$ and Col1 $\alpha 2$ gene expression [10].

In addition to real-time RT-PCR analysis of osteoblast markers we analyzed bone formation activity of $\alpha 7 \mathrm{KO}$ by means of ToF-SIMS measurement that was recently proved for the investigation of bone composition [15]. Using ToF-SIMS an increase of proline fragment intensity $\left(\mathrm{C}_{4} \mathrm{H}_{6} \mathrm{~N}^{+}\right.$and $\left.\mathrm{C}_{4} \mathrm{H}_{8} \mathrm{~N}^{+}\right)$was detected for $\alpha 7 \mathrm{KO}$ compared to $\alpha 7$ WT. $\mathrm{C}_{4} \mathrm{H}_{6} \mathrm{~N}^{+}$and its derivative $\mathrm{C}_{4} \mathrm{H}_{8} \mathrm{~N}^{+}$are assigned to be fragments of the amino acid proline and therefore parts of collagen type 1 as already well demonstrated by means of ToF-SIMS [16]. The up-regulation of collagen synthesis might also provide an explanation for the increased biomechanical bending stiffness and cortical thickness of female $\alpha 7 \mathrm{KO}$. Results on bone collagen synthesis are contrary to skin collagen synthesis where Arredondo et al. (2003) described a significant down-regulation of Col1 $\alpha 1$ in $\alpha 7 \mathrm{KO}$ [11]. With respect to skin and bone the discrepancy in collagen synthesis might be explained by its generation by fibroblast in skin and osteoblasts in bone, respectively.

ToF-SIMS analysis was also used to determine trabecular calcium ion content that was identified by characteristic mass signals [15]. We observed a decrease of calcium content in trabecular center and trabecular edge of $\alpha 7 \mathrm{KO}$ in comparison to $\alpha 7 \mathrm{WT}$. Mouse trabeculae are slim thereby the center is a region where differentiated lamellar bone is found and the edge presents the region with woven bone and osteoid. Our result on female $\alpha 7 \mathrm{KO}$ leads us to the assumption that $\alpha 7 \mathrm{KO}$ trabecular edge consists of lamellar bone and that these lamellar bone has reduced calcium content. However, this is highly speculative and needs to be further analyzed in future studies. In addition it has to be concerned that small effects might be missed because of the low number 

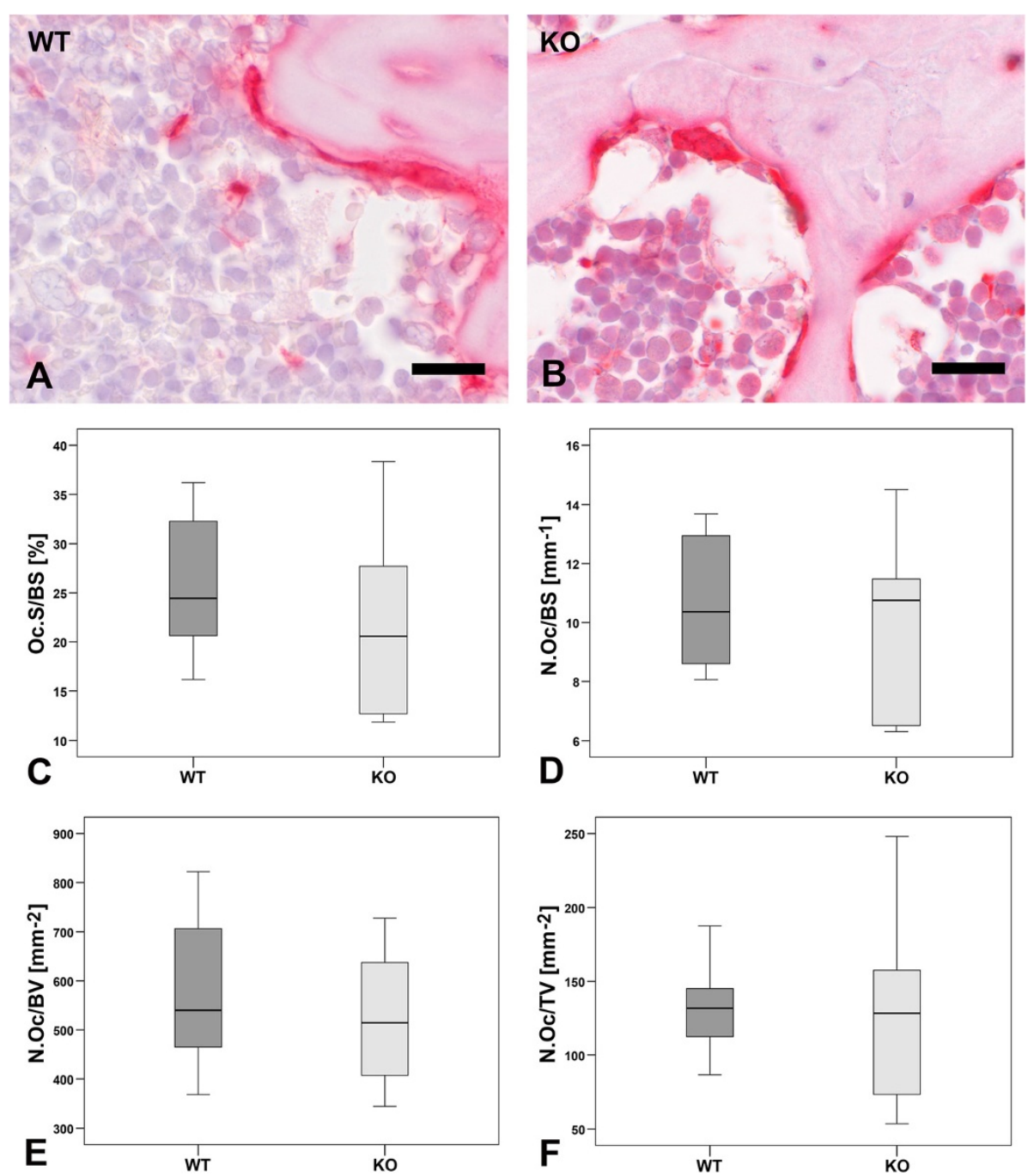

Figure 7 Osteoclast histomorphometry. Osteoclasts were determined by enzyme histochemical labeling of tartrate resistant acidic phosphatase (TRAP, A-B). The parameters osteoclast surface to bone surface (Oc.S/BS, C), osteoclast number to bone surface (N.Oc/BS, D), osteoclast number to bone volume (N.Oc/BV, E), and osteoclast number to tissue volume (N.Oc/TV, F) of a7KO (KO) compared to a7WT (WT) were calculated. Data presented as box plots with the median indicated by solid line within the box, percentile 25 and 75 as bottom and top of the box, and percentile 0 and 100 as whiskers. Small circles represent data beyond 3x SD. Bar: $20 \mu \mathrm{m}$.

of analyzed animals, possible population variability, and the eventuality that while eliminating $\alpha 7-n A C h R$ gene other nAChR might be up-regulated that might be able to take over functions of $\alpha 7$-nAChR. General expression analysis of $\alpha 7 \mathrm{KO}$ compared $\alpha 7 \mathrm{WT}$ would be of high interest for bone as well as for other organs.

Bone remodeling depends on osteoblast as well as osteoclast activity. Therefore we investigated currently gene expression of osteoclast marker cathepsin $K$ that degrades collagen type 1 and is therefore an important enzyme during bone resorption [27]. In female $\alpha 7 \mathrm{KO}$ cathepsin $\mathrm{K}$ gene expression is significant down-regulated. Thus, it can be speculated that less osteoclasts are generated or that generation of degrading enzymes in osteoclasts is down-regulated in $\alpha 7 \mathrm{KO}$. Since nicotine is known to stimulate osteoclast differentiation and bone degradation [28] the reduction of nicotinic receptors in $\alpha 7 \mathrm{KO}$ might provoke the down-regulation of cathepsin $\mathrm{K}$ expression. In male $\alpha 7 \mathrm{KO}$ we did not investigate cathepsin $\mathrm{K}$ gene expression in our previous study [10]. In addition to gene expression analysis osteoclast activity can be studied by e.g. TRAP enzyme histochemistry and subsequent histomorphometry. Our results showed no significant changes in the osteoclast histomorphometrical results of female $\alpha 7 \mathrm{KO}$ compared to $\alpha 7 \mathrm{WT}$. Histomorphometrical analyses have the limitation that they are done on slices which borders the method to 2-deminsions. Therefore, we performed additional 3D Micro-CT analysis as we already did in our previous study with male $\alpha 7 \mathrm{KO}$ [10]. The balance of bone formation and degradation is described by 


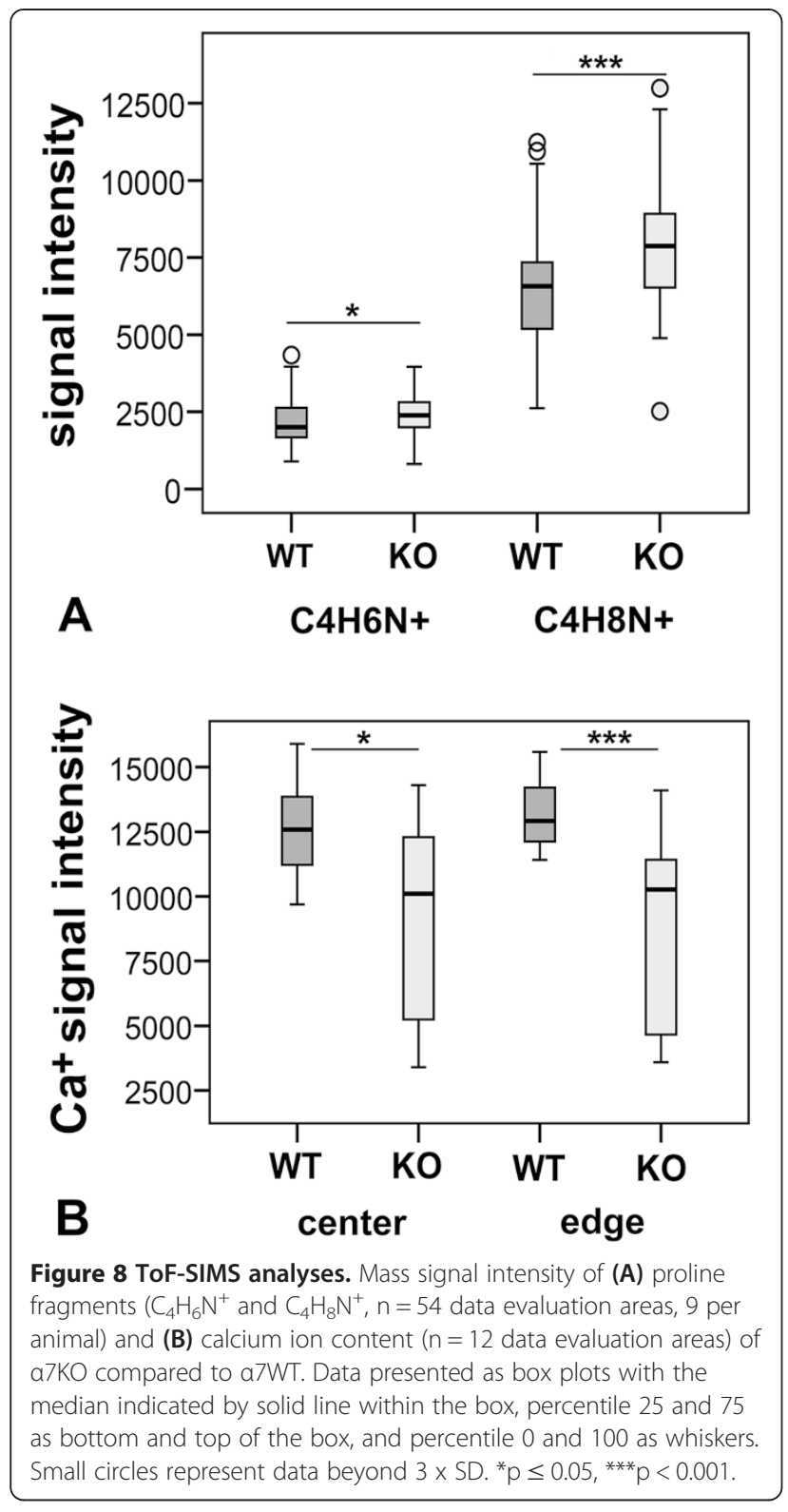

parameters as BV/TV, BS/TV, Tb.Th, Tb.Sp, and SMI. In bone loss this parameters are demoted except SMI which is increased. In female $\alpha 7 \mathrm{KO}$ a decrease of SMI but an increase of BV/TV and Tb.Th was measured for vertebrae L1 whereas analysis of vertebrae Th13 and femur did not result in significant differences. All three analyzed bones are well attributed to human osteoporosis [29]. Thus, in addition to biomechanical testing, determination of BMD and ToF-SIMS analysis also Micro-CT investigation of trabecular bone does not show any evidence of bone loss in $\alpha 7 \mathrm{KO}$. In contrast to $\alpha 7 \mathrm{KO}$ significant bone loss was determined in mice with deficiency of $\mathrm{nAChR}$ subunit $\alpha 2$ [5] and mAChR M3 [9,10] whereas double knockout of $\alpha 7 \beta 2 \mathrm{nAChR}$ resulted in significant bone mass accrual [23].
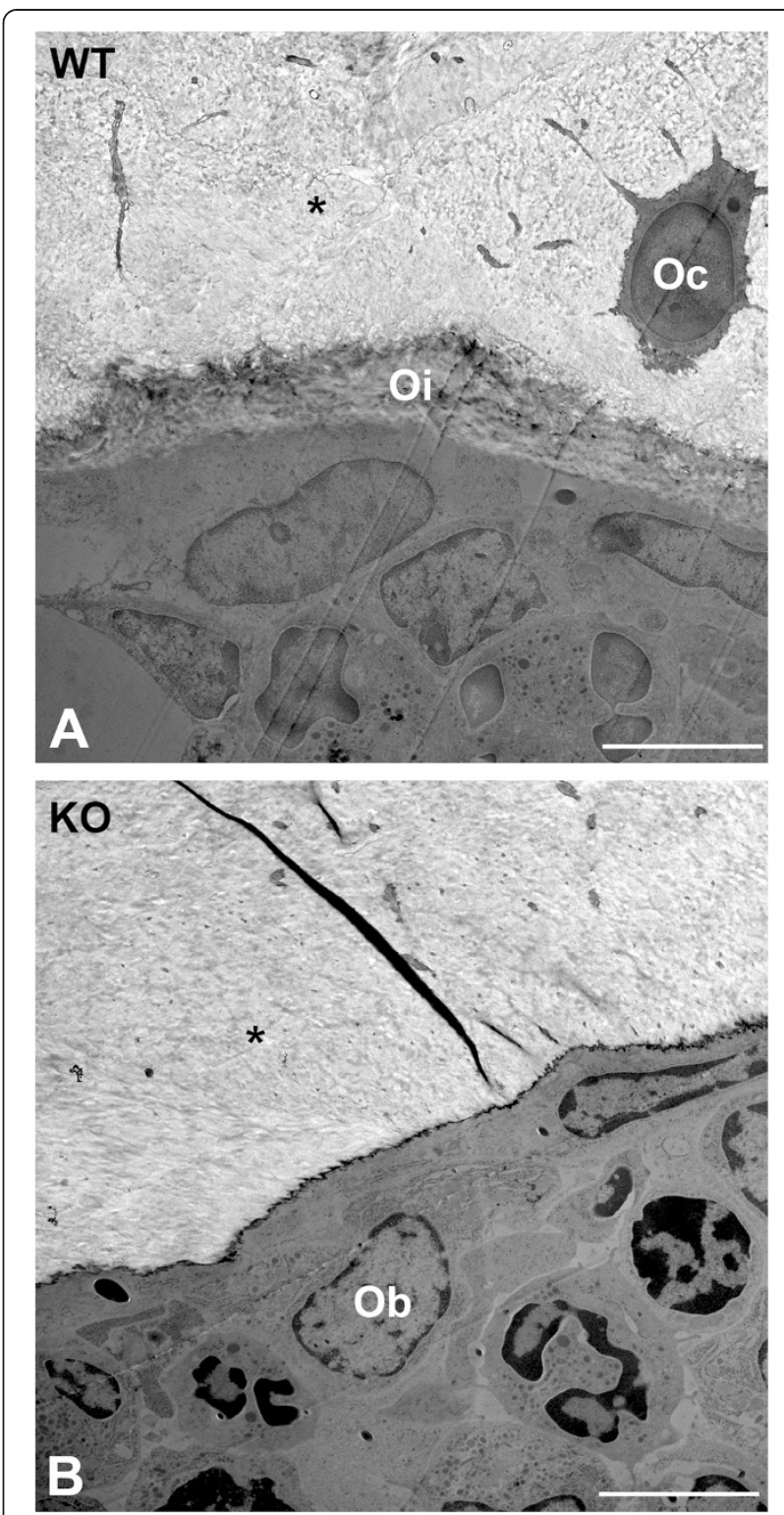

Figure 9 Transmission electron microscopy. Ultrastructure of vertebrae L4 of a7WT (A) and a7KO (B). Oi: osteoid, Oc: osteocyte, Ob: osteoblast. Bar: $5 \mu \mathrm{m}$.

Besides, the non-neuronal presence of $\alpha 7-n A C h R$ and its supposed impact in bone remodeling it was proven that bone is under neuronal control [5,30]. Blood flow of the common carotid artery is increased by nicotine stimulation through $\alpha 7-\mathrm{nAChR}$ in cat medulla [31,32]. In addition to the central nervous system also the autonomic nervous system controls blood flow. In $\alpha 7 \mathrm{KO}$ a decreased baroreflexmediated tachycardia was detected indicating that $\alpha 7$ nAChR participate in the autonomic reflex that maintains blood pressure homeostasis [33]. Blood circulation of bone is also regulated via the autonomic nervous system. Stimulation of sympathetic nerves decreased bone blood flow 
[34] and diminished bone mass accrual [35]. However, current study did not reveal any regulation in bone blood flow through $\alpha 7-n A C h R$ because no significant change was observed in bony blood flow of $\alpha 7 \mathrm{KO}$.

\section{Conclusions}

In the present study, we identified differences in bone strength, composition and microarchitecture of female $\alpha 7 \mathrm{KO}$. Our results showed that deficiency $\alpha 7-\mathrm{nAChR}$ did not induce bone loss in contrast to nAChR subunit $\alpha 2$ [5] and mAChR M3 $[9,10]$. Similar to male mice with gene deficiency of $\alpha 7 \beta 2-\mathrm{nAChR}$ [23] female $\alpha 7 \mathrm{KO}$ revealed an increase in bone mass. However, the presently detected bone mass accrual could not be detected in male $\alpha 7 \mathrm{KO}$ as determined previously [10]. Thus, bone strength and composition are different in female and male $\alpha 7 \mathrm{KO}$. Further studies are necessary to determine gender specific effect of $\alpha 7-n A C h R$ in bone homeostasis.

\section{Competing interests}

The authors declare that they have no competing interests.

\section{Authors' contributions}

Study design: KSL, TB, LD, MKa, OK. Study conduct: KSL, AL, LD, Al, CH, RS, OK. Data collection: ÖY, MKn, IP, VK, MM, AH, PS, YL. Data analysis: KSL, MKn, ÖY, MR, TB, MKa, MR, Data interpretation: KSL, ÖY, MKn, IP, VK, AH, PS, MR, TB, $\mathrm{YL}$, MKa, Al, CH, RS, OK, LD. Drafting manuscript: KSL, ÖY, MKn, VK, IP, AH, PS, $M R, T B, Y L, M K a, L D$. Revising manuscript content: MM, AL, Al, CH, RS, OK. Approving final version of manuscript: KSL, ÖY, MKn, IP, VK, MM, AH, PS, MR, $\mathrm{TB}, \mathrm{YL}, \mathrm{MKa}, \mathrm{AL}, \mathrm{LD}, \mathrm{Al}, \mathrm{CH}, \mathrm{RS}, \mathrm{OK}$. KSL takes responsibility for the integrity of the data analysis.

\section{Acknowledgements}

The authors thank Ivonne Bergen, Rainer Braun, Olga Dakischew, Martina Fink, Patrizia Horny, Gunhild Martels, and Ida Oberst, for skillful technical assistance. This study was supported by DFG (SFB/TRR 79 projects B7, B8, M5, T1, Z3) and HMWK (LOEWE research focus 'Non-neuronal cholinergic systems').

\section{Author details}

'Laboratory for Experimental Trauma Surgery, Justus-Liebig University Giessen, Kerkraderstr. 9, 35394 Giessen, Germany. ${ }^{2}$ Institute for Physical Chemistry, Justus-Liebig University Giessen, Heinrich-Buff-Ring 58, 35392 Giessen, Germany. ${ }^{3}$ Institute of Radiology, University Medical Center Erlangen, Friedrich-Alexander University Erlangen-Nuernberg, Palmsanlage 5, 91054 Erlangen, Germany. ${ }^{4}$ Department of Medical Physics in Radiology, German Cancer Research Center, INF 280, D-69120 Heidelberg, Germany. ${ }^{5}$ Department of Radiology, Justus-Liebig University Giessen, Schubertstr. 81, 35392 Giessen, Germany. ${ }^{6}$ Department of Diagnostic and Interventional Radiology, BG Trauma Hospital, Friedberger Landstraße 430, 60389 Frankfurt/ Main, Germany. ${ }^{7}$ Institute of Orthopaedic Research and Biomechanics, Center of Musculoskeletal Research University of Ulm, Ulm, Germany. ${ }^{8}$ Department of Trauma Surgery Giessen, University Hospital of Giessen-Marburg, Justus-Liebig University Giessen, Rudolf-Buchheim-Str. 7, 35392 Giessen, Germany. 'Department of Orthopedics and Trauma, Zentralklinik Bad Berka, Robert-Koch-Allee 9, 99437 Bad Berka, Germany.

Received: 18 July 2014 Accepted: 12 January 2015

Published online: 31 January 2015

\section{References}

1. Changeux JP. The nicotinic acetylcholine receptor: the founding father of the pentameric ligand-gated ion channel superfamily. J Biol Chem. 2012;287:40207-15.

2. Albuquerque EX, Pereira EF, Alkondon M, Rogers SW. Mammalian nicotinic acetylcholine receptors: from structure to function. Physiol Rev. 2009;89:73-120.
3. Wessler I, Kirkpatrick CJ. Acetylcholine beyond neurons: the non-neuronal cholinergic system in humans. Br J Pharmacol. 2008;154:1558-71.

4. Gahring LC, Rogers SW. Neuronal nicotinic acetylcholine receptor expression and function on nonneuronal cells. AAPS J. 2005;7:E885-94.

5. Bajayo A, Bar A, Denes A, Bachar M, Kram V, Attar-Namdar M, et al. Skeletal parasympathetic innervation communicates central IL-1 signals regulating bone mass accrual. Proc Natl Acad Sci U S A. 2012;109:15455-60.

6. Sato T, Abe T, Chida D, Nakamoto N, Hori N, Kokabu S, et al. Functional role of acetylcholine and the expression of cholinergic receptors and components in osteoblasts. FEBS Lett. 2010;584:817-24.

7. Liu PS, Chen YY, Feng CK, Lin YH, Yu TC. Muscarinic acetylcholine receptors present in human osteoblast and bone tissue. Eur J Pharmacol. 2011;650:34-40.

8. En-Nosse M, Hartmann S, Trinkaus K, Alt V, Stigler B, Heiss C, et al. Expression of non-neuronal cholinergic system in osteoblast-like cells and its involvement in osteogenesis. Cell Tissue Res. 2009;338:203-15.

9. Shi Y, Oury F, Yadav VK, Wess J, Liu XS, Guo XE, et al. Signaling through the M(3) muscarinic receptor favors bone mass accrual by decreasing sympathetic activity. Cell Metab. 2010;11:231-8.

10. Kliemann K, Kneffel M, Bergen I, Kampschulte M, Langheinrich AC, Durselen $L$, et al. Quantitative analyses of bone composition in acetylcholine receptor M3R and alpha7 knockout mice. Life Sci. 2012;91:997-1002.

11. Arredondo J, Nguyen VT, Chernyavsky Al, Bercovich D, Orr-Urtreger A, Vetter $\mathrm{DE}$, et al. Functional role of alpha7 nicotinic receptor in physiological control of cutaneous homeostasis. Life Sci. 2003;72:2063-7.

12. Pietschmann P, Rauner M, Sipos W, Kerschan-Schindl K. Osteoporosis: an agerelated and gender-specific disease-a mini-review. Gerontology. 2009:55:3-12.

13. Henss A, Rohnke M, Knaack S, Kleine-Boymann M, Leichtweiss T, Schmitz P, et al. Quantification of calcium content in bone by using ToF-SIMS-a first approach. Biointerphases. 2013;8:31.

14. Henss A, Rohnke M, El Khassawna T, Govindarajan P, Schlewitz G, Heiss C, et al. Applicability of ToF-SIMS for monitoring compositional changes in bone in a long-term animal model. J R Soc Interface. 2013;10:20130332.

15. Malmberg $P$, Nygren $H$. Methods for the analysis of the composition of bone tissue, with a focus on imaging mass spectrometry (TOF-SIMS). Proteomics. 2008;8:3755-62.

16. Sanni OD, Wagner MS, Briggs D, Castner DG, Vickerman JC. Classification of adsorbed protein static ToF-SIMS spectra by principal component analysis and neural networks. Surf Interface Anal. 2002;33:715-28.

17. Orr-Urtreger A, Goldner FM, Saeki M, Lorenzo I, Goldberg L, De Biasi M, et al Mice deficient in the alpha7 neuronal nicotinic acetylcholine receptor lack alpha-bungarotoxin binding sites and hippocampal fast nicotinic currents. J Neurosci. 1997;17:9165-71.

18. Shelukhina IV, Kryukova EV, Lips KS, Tsetlin VI, Kummer W. Presence of alpha7 nicotinic acetylcholine receptors on dorsal root ganglion neurons proved using knockout mice and selective alpha-neurotoxins in histochemistry. J Neurochem. 2009:109:1087-95.

19. Rontgen V, Blakytny R, Matthys R, Landauer M, Wehner T, Gockelmann M, et al. Fracture healing in mice under controlled rigid and flexible conditions using an adjustable external fixator. J Orthop Res. 2010;28:1456-62.

20. Brix G, Semmler W, Port R, Schad LR, Layer G, Lorenz WJ. Pharmacokinetic parameters in CNS Gd-DTPA enhanced MR imaging. J Comput Assist Tomogr. 1991;15:621-8.

21. Van't Hof R, Rose L, Daroszewska A. Open source software for semi-automated histomorphometry of bone resorption and formation parameters. Bone Abstracts. 2013;05:210.

22. Dempster DW, Compston JE, Drezner MK, Glorieux FH, Kanis JA, Malluche H, et al. Standardized nomenclature, symbols, and units for bone histomorphometry: a 2012 update of the report of the ASBMR Histomorphometry Nomenclature Committee. J Bone Miner Res. 2013;28:2-17.

23. Somm E, Guerardel A, Maouche K, Toulotte A, Veyrat-Durebex C, RohnerJeanrenaud $F$, et al. Concomitant alpha7 and beta2 nicotinic AChR subunit deficiency leads to impaired energy homeostasis and increased physical activity in mice. Mol Genet Metab. 2014;112:64-72.

24. Govindarajan P, Schlewitz G, Schliefke N, Weisweiler D, Alt V, Thormann U, et al. Implications of combined ovariectomy/multi-deficiency diet on rat bone with age-related variation in bone parameters and bone loss at multiple skeletal sites by DEXA. Med Sci Monit Basic Res. 2013;19:76-86.

25. Avale ME, Faure P, Pons S, Robledo P, Deltheil T, David DJ, et al. Interplay of beta2* nicotinic receptors and dopamine pathways in the control of spontaneous locomotion. Proc Natl Acad Sci U S A. 2008;105:15991-6. 
26. Rothem DE, Rothem L, Soudry M, Dahan A, Eliakim R. Nicotine modulates bone metabolism-associated gene expression in osteoblast cells. J Bone Miner Metab. 2009;27:555-61.

27. Avnet S, Lamolinara A, Zini N, Solimando L, Quacquaruccio G, Granchi D, et al. Effects of antisense mediated inhibition of cathepsin K on human osteoclasts obtained from peripheral blood. J Orthop Res. 2006;24:1699-708.

28. Henemyre CL, Scales DK, Hokett SD, Cuenin MF, Peacock ME, Parker MH, et al. Nicotine stimulates osteoclast resorption in a porcine marrow cell model. J Periodontol. 2003;74:1440-6.

29. Warriner AH, Patkar NM, Curtis JR, Delzell E, Gary L, Kilgore M, et al. Which fractures are most attributable to osteoporosis? J Clin Epidemiol. 2011;64:46-53.

30. Eimar H, Tamimi I, Murshed M, Tamimi F. Cholinergic regulation of bone J Musculoskelet Neuronal Interact. 2013;13:124-32.

31. Kuo JS, Leung YM, Lin NN, Lee TJF, Gong CL. Nicotine stimulation of the medulla increases blood flow of the common carotid artery in cats. Autonom Neurosci-Basic Clin. 2010;152:49-54

32. Gong $C L$, Leung $Y M$, Huang YP, Lin NN, Hung YW, Lee TJF, et al. Nicotine activation of neuronal nitric oxide synthase and guanylyl cyclase in the medulla increases blood flow of the common carotid artery in cats. Neurosci Lett. 2010;486:122-6.

33. Franceschini D, Orr-Urtreger A, Yu W, Mackey LY, Bond RA, Armstrong D, et al. Altered baroreflex responses in alpha 7 deficient mice. Behav Brain Res. 2000;113:3-10.

34. Shim SS. Physiology of blood circulation of bone. J Bone Joint Surg-Am Vol. 1968;A 50:812

35. He JY, Jiang LS, Dai LY. The roles of the sympathetic nervous system in osteoporotic diseases: a review of experimental and clinical studies. Ageing Res Rev. 2011;10:253-63.

\section{Submit your next manuscript to BioMed Central and take full advantage of:}

- Convenient online submission

- Thorough peer review

- No space constraints or color figure charges

- Immediate publication on acceptance

- Inclusion in PubMed, CAS, Scopus and Google Scholar

- Research which is freely available for redistribution 